\title{
SCIENTIFIC RESEARCH: NATURE AND METHODOLOGY
}

\author{
Tetiana Shyriaieva \\ National University of Ostroh Academy, Ukraine \\ E-mail: tetiana.shyriaeva@oa.edu.ua
}

In this edition of scientific journal Problems of Psychology in the $21^{\text {st }}$ Century scientific research is viewed from the perspective of the complexity of its nature and difficulty of its realization. It is no surprise that nowadays psychology goes through the process of its intensive development that results in the appearance of numerous researches in this sphere. However, the question is how novel or scientifically approved the research should be or how much empirical data has it to contain to be claimed scientifically relevant or interesting. It is not simply the issue of cohesion or scientific grammar that is based on a clear understanding of an algorithm of the whole researching activity when the hypothesis is to be formulated. It is unquestioned as scientific research usually means theory, practice, research question and personal experience. It is even not about the structure of any qualitative research as it in most cases contains general overview and research question that is masterly organized in introduction, discussion of literature or the section of topic discourse. It rather means the necessity to dispute the methodological aspects of any scientific work that is a research design and methods that help gather data and analyse it, proving the trustworthiness of the study. However, methodology and set of scientific methods used in the research are to be viewed as two different notions.

It seems no research is ever possible unless a scientist is certain about the intention of the research or its purpose that is in most cases embedded in the topic of the research and its general idea. It provides a clear vision of the matter and develops scientific individuality of its author. However, the nature of scientific research is quite dubious. On the one hand, it is a creative process that presupposes ideological freedom of its researcher. This underlines the importance of scientist's intuition, which influences the efficiency of the research. On the other hand, the research is said to be accomplished if the scientist clearly understands its nature, manages to develop it so that no ambiguity is ever possible, and discovers the object that is deemed to provoke further discussion and development in that particular field. In both cases, to be efficient, scientific research is to evoke interest in both the scientist and the potential reader. Thus it occurs reasonable to analyse the integral elements of scientific research and to contemplate its methodological nature.

Scientific research in psychology is an odyssey that contributes to the general knowledge by widening its theoretical borders and awarding it with new creative and insightful ideas. It states the fact that scientific inquiry means theoretical consideration of the matter under analysis and empirical research. Thus the formal theory or the way the issue is reviewed in the literature should correspond to the tacit theory of the scientist, which is a pure reflection of their understanding of the matter. In most cases, scientific research undergoes transformation from observational analysis of the literature, the concepts and models to personal theoretical assumption. Anyhow, this process presupposes scientist's clear understanding of the issue that is followed by the selective process of scientific methods which can be used for analysis and will regulate the adequacy of a particular procedure. As far as the purposes of the researcher are to explore, explain and describe in a proper language the phenomenon of the scientist's interest, scientific studies are of the explanatory and descriptive nature that can include empirical data and figures.

It is here to say that the methodology is understood as a clear setting of the research but not 
simply as the set of methods used for getting scientifically valid results. Methodology is widely understood as a hierarchy that consists of at least three levels of methods. The initial one is made of general methodological overview that presents an examination of philosophical approach to any phenomenon that reflects general processes, such as the peculiarities of the human psyche and its genesis. The second one includes special methods that belong to a specific or particular field of science. In other words, general philosophical methods are applied to a particular branch that demonstrates how a general problem is narrowed to a specific issue which is under the analysis. It is when general methods are viewed in relation to a specific question or issue. The third level is a unity of specific methods of the research. It is so-called specific methodology or practical aspect of the research that is characterized by data analysis and scientist's vision of further topic development.

To assume, it should be noted that scientific research is a unique phenomenon that is characterized by its specific nature and requirements to be met. Here the analytic process of the scientist should not be devalued. However, it provides the creative act with its proper due. It is vital for the scientific research to be methodologically coherent and apt. Moreover, empirical research is not exclusively about the data that is acquired as a result of the research, even though it is quite preferable, it is not only the experiment, but logical assumption and a summary of all the findings that result in the new empirical law formulation. 